\title{
Renata Šamo \\ READING: Some Theoretical Issues and Their Pedagogical Implications
}

Tn the past there have been many influential theories and some of these have been reflected in a number of methods of teaching reading and the publishing of materials to support the methods. However, the controversies about reading have offered no single definitive all-encompassing theory or method concerning the crucial questions: what is reading, what is it that readers have to do, and how is reading to be taught? Nowadays it seems important for teachers to have some recent insights into reading as a dynamic process which involves author-text-reader interaction, that is, to make students, even young learners, aware of intertextual as well as intratextual interaction in order to help them deal with a wide range of information sources on their own.

\section{Introduction}

In order to answer how children learn to read, we need some broader understanding about a complex process that has perhaps generated more controversy than any other aspect of language teaching. The discussions and debates have thus related to beliefs about what reading is, what it is that readers have to do and how reading is to be taught. In the past there have been many influential theories and some of these have been reflected in a number of methods of teaching reading and the publishing of materials to support the methods.

Anyway, the controversies about reading have offered no single definitive all-encompassing theory or method, and one of the things teachers have to do in order to feel in control is to inform themselves. The aim of this chapter is to provide a brief historical overview and then to look more closely at some recent significant developments within the theory of L2 reading, inevitably influenced by some accounts of L1 reading.

\section{Reading: Models and Methods}

Although there has been a range of models, based on different theoretical assumptions of the process of reading, the three following categories have been presented in literature on reading as the most remarkable ones: the bottom-up model, the top-down model and the interactive models. Presenting two contrasting views, the first two models have aroused discussions on the concept of reading with some interactive models as their direct result. 
Before providing a historical perspective on the issues, it is necessary to define $a$ model of reading. The term refers to "... a systematic set of guesses or predictions about a hidden process, which are then subjected to "testing" through experimental studies" (Davies, 1995:57).

\subsection{Bottom-up Model}

The bottom-up or outside-in model is known to be the first abstract theory of reading. According to its basic assumptions, reading is viewed as the sequential processing of text: from letters to sounds, to words, to sentences and finally to meaning and thinking. However, it should be noted that one of the main weaknesses of such a simplified concept of reading is as follows: it is hardly possible to suppose that fluent adult readers pay equal attention to each letter or each word in text.

Today it is quite clear that progression through text, implied by the bottom-up model, cannot reflect the sequence of reading instruction in educational contexts because it is assumed that the stated serial processing imposes a heavy burden on shortterm or working memory. In beginning to read, such a burden can be ineffective, forcing the reader to rely heavily on the lower-level sources of information such as graphophonemic correspondences.

However, the bottom-up model was used to support approaches to the teaching of reading which focused attention on decontextualized reading both in L1 and L2 reading. The distinctive feature of the main early methods of reading - alphabetic, phonic and look-and-say method - is the unit to be used in the beginning reading instruction. Starting with letters or sounds, and how important the phonic knowledge is in the initial recognition of meaningful words, phrases or sentences - represented the key issue among educationalists during the first half of the $20^{\text {th }}$ century.

The initial conventional view of reading as a hierarchy of specific skills, a taxonomy of behaviours, that are to be gradually acquired by applying a firmly structured reading programme, influenced the approach to the teaching of reading that was primarily focused on the ability to read words.

In the 1970s, however, a group of influential psycholinguists, headed by F. Smith and K. Goodman, changed the previous behaviouristic view of reading into a new concept of reading as a psycholinguistic process.

\subsection{Top-down Model}

In sharp contrast to the bottom-up model, the top-down or inside-out model implies the reverse of the processing sequence, including thinking and meaning at a very early stage of reading. Minimal attention is thus paid to grapho-phonemic correspondences, but special emphasis is placed on the higher-level sources of information, predominantly on guessing and prediction. 
The essence of the top-down model is to be found in the well-known definition of reading as "a psycholinguistic guessing game". Not only has K. Goodman contributed to attempts at defining reading, but he also redirected the previous concept of reading as mechanical decoding. As is known, the psycholinguistic model relies heavily on information stored in memory. According to Goodman, the skilled reader, in his search for meaning, tends to pay maximum attention to the context at the expense of attention to visual information in text.

The view of reading as "the reduction of uncertainty" (Wallace, 1992:39) reveals that F. Smith has also stressed the importance of selectivity during the process of reading. The author has argued that the reader is allowed to make a choice of his own in order to grasp a proper meaning of the text being read. However, F. Smith has claimed that the reader's choice is restricted by his knowledge of relevant features of language and text (linguistic knowledge) and by his knowledge of the world (schematic knowledge). Therefore, the brain, with its prior knowledge of the world, of how texts are written, and of grammatical conventions, appears to contribute more information to reading than the visual symbols on the printed page. Deeply convinced that "children learn to read only by reading", the author has been a serious opponent to the decontextualized teaching of reading.

The change from decontextualized reading to reading in the context of meaning has also resulted in some new reading goals. As we have already pointed out, earlier approaches tended to emphasise accurate word recognition not only as the reading goal but also as the standard of successful reading of children (and adults, as well). According to the authors of the psycholinguistic model, however, the reconstruction of the writer's ideas and messages, with meaning in the central role, has become the ultimate reading goal. In order to approximate the writer's intended message, the skilled reader interacts with the text, using the existing knowledge as well as the information on the page.

Accounts of reading as a selective process show that the two theorists have not considered each source of information to be equally important to each reader. Moreover, the main proponents of the alternative view of reading have also pointed out the wrong assumption that insistence on error-free recognition of each word on the page or on the correct interpretation of each sound in the text can guarantee a better understanding.

The implication for teaching is inescapable. Instead of assuming that children can only read what they have been taught, Smith and Gooodman have assumed that they can only read what they understand and can interact with, drawing on their experi-

Goodman published his famous article "Reading: A Psycholinguistic Game" in Journal of the Reading Specialist 6 (1967). 
ences and concepts. Due to the very strong emphasis on reading aimed at understanding meaning, silent reading is the preferred mode because reading aloud is believed to make additional demands on the person reading, often resulting in a loss of real meaning. Consequently, teachers are the ones who help their students to select the most productive clues at different levels, while students become active partners during the process, respecting the support of adults or the support of their more skilled classmates. A proper selection of meaningful texts is then viewed as one of the key issues of the new approach to reading.

The first serious attempt at introducing reading into the context of meaning and the real reading needs of children was represented by the story method which tried to promote the importance of the natural interrelation between spoken and written language. Although the launch of stories at an early stage of teaching was welcomed as a rescue from those monotonous drills in identifying words on flash cards, the initial enthusiasm of many teachers gave way to dissatisfaction; so the search for more interesting reading materials continued. They still lacked some new materials which could make the teaching of reading much more motivating and enjoyable.

\subsection{Interactive Models ${ }^{6}$}

The importance of the visual and cognitive processing of text is best implied by the interactive model of reading, with the reading process largely following the bottom-up model but with input from the top-down processes when necessary.

Evidence for the currently accepted view of reading comes primarily from eyemovement data, which has become available over the past 10 or 15 years. The development of sophisticated but powerful laser and computer technology has permitted much more accurate recording of eye movements. It indicates that under normal conditions word recognition occurs very rapidly, generally in less than a quarter of a second, and that it occurs automatically, without the reader making use of context.

Hence, there is no time for generating and testing all the hypotheses that the psycholinguistic model implies. The current view best fits the assumption of rapid, automatic, context-free word recognition in the normal reading of fluent readers. However, this model does not deny the use of context as an aid to comprehension, nor is phonemic decoding ruled out, but these are both assumed to be aids to word recognition which are often unnecessary for fluent readers. It is in this respect that reading is now regarded as an interactive-compensatory process. ${ }^{7}$

6 A brief overview of some influential interactive models can be found in Davies (1995).

7 In order to refer to one of the recent views of reading, we have accepted the interactive model, proposed by K. Stanovich. The author presented his theory in the article "Towards an InteractiveCompensatory Model: Individual Differences in the Development of Reading Fluency" (Reading Research Quaterly 16, 1980, 32-71). 
What are the main pedagogical implications? First of all, it is important to make the distinction between being a fluent reader and learning to become a fluent reader. While a child is learning to read, the compensatory part of the reading process is vital. When children are building up confidence and gradually extending their sight vocabulary, they need to use all the tools available, including intelligent guesswork. The recent view of reading has consequently led to some new demands for the child regarding his repertoire of reading strategies, especially phonic knowledge and phonemic awareness.

Children have to learn how the smallest units of spoken sound, phonemes, correspond to their written forms, graphemes, and, in order to do this successfully, they need to develop the ability to hear sounds in their heads and categorize them. Children should know that a single change of phonemes or graphemes can produce a quite different word with a very different meaning, for example hot and pot.

Some recent British research, done by L. Bradley, P. Bryant and U. Goswami, has centred attention on children's awareness of the phonemic structure of spoken words as a strong indicator of future success in learning to read and progress in spelling. It has been shown that there is a clear link between the early development of sensitivity to rhyme or alliteration and progress in reading. For many children this sensitivity develops informally through exposure to nursery rhymes long before they go to school. One of the most significant recent developments has therefore been in our understanding of phonics in children's reading and in particular the contribution that phonemic awareness can make towards success in reading.

During the 1980s, the development of life-long reading habits in accordance with the real reading needs of readers turned out to be the ultimate goal of the reading instruction. The new goal also required a new approach of teachers to their task. Instead of helping children how to learn to read, teachers became aware of their additional responsibility related to the selection of well-written stories and a concern for individual differences among children, including their reading abilities, too.

Dissatisfaction with a vast range of graded reading schemes caused louder and louder claims for the introduction of children's literature of high quality which could meet the social, emotional, aesthetic, and, above all, cognitive demands of children in $\mathrm{L} 1$ and $\mathrm{L} 2$ reading. So, the real books method has been considered quite appropriate to the holistic concept of communication and teaching of language skills.

More recently, L. Waterland has published an interesting booklet, describing a specific "apprenticeship approach" to teaching reading. Read with Me (1985) has become a kind of handbook for parents, children's care-takers and teachers. By adding a social dimension to the psycholinguistic concept of reading, Waterland has supposed that children who perceive reading at home and reading at school as a similar activity seem 
willing to share their reading experiences with others. Such shared reading is based on the proposition ${ }^{8}$ that in "many ways the acquisition of written language is comparable with that of spoken language" (Waterland, 1985:13). Its secret lies in adults' reading to and with the child as they spoke to and with him while he was learning to talk.

What are the weak points of using real books? The most serious criticism start from the assumption that reading can be learned without direct teaching and that reading can only be taught either through reading schemes or through real books. Besides, all books that are not part of a reading scheme are considered "good", whereas all reading scheme books are not. The real book approach also suffers because it became associated with another assumption, that is, phonic teaching is not necessary. Huge public controversy about these issues led to a number of government-initiated surveys during the 1990s.

\section{L2 Reading: Theory and Acquisition}

Similar trends to those outlined above can be observed in the theory of second language reading. The most important aspects of learning to read in a second language have also resulted from the theoretical and practical considerations during the last two decades. Besides, the research on L2 reading acquisition has broadened our understandings about the process of reading as a complex interaction at different levels. According to K. Koda, three fundamental differences between L1 and L2 reading should be noted:

1. the $\mathrm{L} 2$ reader has prior reading experience

2. L2 reading involves at least two languages

3. L2 reading ability develops before adequate oral fluency is achieved.

I. van Wijnendaele (1998) has pointed out, however, that the factors listed above do not include socio-cultural factors which are known to influence L2 reading acquisition. The same author has also given a review of the most influential theories that have been proposed for L2 reading acquisition. Some researchers explain the differences between L1 and L2 readers predominantly in terms of automatic versus controlled processes. Other theorists explain these differences in terms of bottom-up versus top-down processing, while a third group of authors deals with the question whether reading problems in a second language are reading problems or language problems.

\subsection{Automatic versus Controlled Processing}

Learning to read, viewed as the acquisition of complex cognitive skills, implies two types of operations - automatic and controlled processes. Automatic processes oc-

There are five of them, see in Read with Me. The cited proposition is the first one in the list. 
cur quickly without requiring special attention, whereas controlled processes are slow and source demanding. According to the first group of researchers, reading acquisition can be considered as a progressive transition from controlled to automatic processing. Learners beginning to read try to cope with phonological information in a controlled way (one-by-one grapho-phonemic matching) until they have a command of word decoding. The controlled processes then shift to syntax and semantics. The more automatic decoding abilities he has, the more attention the reader can direct to sentence comprehension. The extent to which certain reading skills have become automatic or still require controlled processing can be indicated by different strategies used by good and poor readers. Good readers can use their syntactic and semantic knowledge of the language to grasp the meaning of the text. In contrast, poor readers have less efficient strategies available.

The differences between $\mathrm{L} 1$ and $\mathrm{L} 2$ reading in terms of the transition from controlled to automatic processing have indicated more syntactic errors than lexical ones in poor L2 readers. This finding has generally been ascribed to the fact that native speakers have a well- developed syntactic knowledge in spoken language which enables them to prevent syntactic errors in reading. L2 readers, however, lack the effortless access to this information. Reading performance profits from the presence of wellmastered, automatic processing in the spoken language, as we have seen above.

Another important issue in the discussion on automatic versus controlled processes is the extent to which $\mathrm{L} 2$ reading acquisition can profit from the existence of automatic reading processes in the first language. It should be noted here that early studies into how and when the first language influences the second language mostly examined the negative outcomes of cross-linguistic transfer in reading. Later, researchers started to look for positive transfer as well. They have argued that positive transfer can provide information on how to make instructions in L2 teaching optimal. Their main concern has been to help the learner to profit from competences already achieved in the mother tongue. Moreover, it has been believed that $\mathrm{L} 2$ learners must be aware of the formal structural similarities between languages, as these are not enough for transfer to occur.

\subsection{Bottom-up versus Top-down Processing}

We have already explained that the distinctive feature between these two approaches is the nature of their input. In the literature on L2 reading acquisition, however, a lot of attention has been paid to top-down processes that are also called concept-based processes. This theory of reading emphasises the importance of background knowledge for understanding written text. Due to the fact that the reader's background knowledge is strongly influenced by his own culture, L2 readers may have difficulties in building the right schema for the text they are reading. In the 1970s and 1980s, a number of theo- 
ries have been proposed with the basic message that reading comprehension depends critically on the reader's ability to relate information from the text to already existing background knowledge, which may generate most of L 2 reading problems.

Being among the first theorists who pointed out the limitations of the top-down way of information processing, D.E. Eskey (as cited in Alderson, 2000) has argued that the stated processes consider fluent reading as correct text understanding and thus de-emphasise the perceptual and decoding aspect of the reading process. According to Eskey, this model may be accurate for fluent readers but underestimates the problems less proficient readers face. The lack of attention to decoding problems, he believes, may produce a distorted picture of the real problems of $\mathrm{L} 2$ readers. The research, done by the second group of authors, has resulted in the conclusion that the influence of bottom-up processes in word recognition decreases as children become more experienced. These processes are then more or less replaced by top-down influences in combination with socio-cultural factors.

However, the problems with the top-down model have turned many researchers to interactive models (see 2.3.), which are based on a constant interaction between bottom-up and top-down processes during reading. Good readers are nowadays considered not only as good text decoders but also as good text interpreters.

\subsection{Language or Reading Problem?}

Are problems in second language reading language or reading problems? The question should be considered within the distinction between the universal and the specific approach.

The supporters of the universal approach have focused their attention on the conditions which inhibit or facilitate the transfer of reading skills from the first to the second language. According to J. Cummins and his often cited Threshold Hypothesis, language transfer is only possible after a threshold level of L2 proficiency has been attained. Cummins' theory has been acknowledged, among others, by J.E. Brisbois (as cited in van Wijnendaele, 1998), as well as his conclusion that reading skills can be transferred between languages, especially in proficient L2 learners. However, this has been criticised for ignoring the cross-linguistic dimension of language processing.

In contrast, the language-specific view is based on the assumption that the linguistic features essential for understanding and producing language are not universal, that is, persons with different language backgrounds use different strategies when reading in a non-native language. According to R. Berman (as cited in van Wijnendaele, 1998), good syntactic knowledge is important. The author has pointed out that successful readers are able to extract meaning from text because they understand its syntactic structure. 
Is $\mathrm{L} 2$ reading a language problem or a reading problem? In his first chapter of Reading in a Foreign Language (1985), Ch. Alderson concluded: '... it appears to be both a language and a reading problem, but with firmer evidence that it is a language problem, for lower levels of foreign language competence, than a reading problem" (p. 24).

The theoretical models of reading outlined above relate to the kind of information readers focus on while reading a text. In the same light, J. Devine suggests that readers can be basically divided into "sound-centred readers" (who pay attention to the graphemic and phonemic aspects of a text) and "meaning-centred readers" (who pay attention to text understanding). As we are mostly concerned about the demanding process of $\mathrm{L} 2$ reading, it may be of particular interest to show a relationship between the theories of reading and the reader's success in text comprehension. According to the same author, the sound-based model of reading, combined with the low L2 proficiency, results in a strongly limited transfer of effective reading abilities from the first to the second language, whereas the negative effects of poor L2 knowledge can be overcome by the meaning-based approach and the reader is permitted to transfer good reading strategies from $\mathrm{L} 1$ to $\mathrm{L} 2$. Although $\mathrm{L} 2$ reading is mostly viewed as a language problem, emotional and socio-cultural factors may also be considered.

L2 reading in its educational context(s) has also reflected similar trends. Learning to read and reading for enjoyment in L1 classrooms have thus been related to intensive reading and extensive reading in $\mathrm{L} 2$ classrooms. The latter distinction is no longer considered useful as recent research has shown that the child's developing competence requires a variety of reading experiences - from word recognition games and pronunciation practice to problem-solving activities. The very recent story-based approach to reading has opened up the matter of using simplified or authentic storybooks with children learning English. Quite obviously, it coincides with the matter of using graded schemes or real books with English-speaking children. The advocates of authentic storybooks have claimed that they provide real language, bringing the real world into the classroom. L2 teachers should know that storybooks, apart from being motivating for children, can " ... trigger a wealth of purposeful language-learning activities " (Ellis $\&$ Brewster, 1991:16). Of course, if they are used in a proper way, and the methodology of using storybooks has been given in the handbook stated above.

\section{Conclusion}

This chapter has shown that the theory of $\mathrm{L} 1 / \mathrm{L} 2$ reading and the teaching of $\mathrm{L} 1 / \mathrm{L} 2$ reading are closely interrelated. Besides, it has indicated that research on such a complex and subtle process can never be static. Recent insights into reading have revealed a gradual move away from a strictly private, individual activity towards a dynamic 
process which involves an author-text-reader interaction. From the teaching point of view, it should be stressed that the process of reading as such implies the so-called intertextual as well as intratextual interaction. So, the teacher is supposed to inform himself in order to make the student aware of all the complexity of reading and to help him become a strategic reader who will be able to deal with a wide range of information sources on his own.

\section{Bibliography}

Alderson, Ch. \& Urquhart, A.H. (1984). Reading in a foreign language. New York: Longman. Alderson, Ch. (2000). Assessing reading. Cambridge: Cambridge University Press.

Davies, F. (1995). Introducing reading. London: Penguin English.

Ellis, G. \& Brewster, J. (1991). The storytelling handbook for primary teachers. London: Penguin English.

Graham, J. \& Kelly, A. (Eds.) (1997). Reading under control: Teaching reading in the primary school. London: Roehampton Institute.

Parker, R. \& Parker, R. (1991). Real reading needs real books. In C.J. Broomfit, J. Moon \& R. Tongue (Eds.), Teaching English to children: From practice to principle (pp. 178-190). Glasgow: Collins ELT.

Van Wijnendaele, I. (1998). Reading in a second language. Psychologica Belgica 38(3/4), 149161.

Wallace, C. (1992). Reading. Oxford: Oxford University Press.

Waterland, L. (1985). Read with me: An apprenticeship approach to reading. Stroud, UK: Thimble Press. 